\title{
Ethnoecological Importance Value (EIV) Methodology: Assessing the Cultural Importance of Ecosystems as Sources of Useful Plants for the Guaymi People of Costa Rica
}

Research

\author{
Héctor Castaneda and John Richard Stepp
}

\begin{abstract}
The study took place in the Guaymi Indigenous Reserve of Coto Brus, in the southern Pacific region of Punta Arenas, Costa Rica. The purpose of the project was to investigate the cultural importance of different successional stages for providing the Guaymi with wild food plants and to test a new methodology for evaluating the ethnoecological importance of each successional stage. Forty six members of the community were interviewed about wild foods. Free listing was used to collect the data from each informant. Then, the abundance of edible plants (those obtained from the interviews) was studied in five different successional stages in the field.
\end{abstract}

This article introduces the Ethnoecological Importance Value (EIV) index that evaluates the ethnoecological importance of ecosystems as sources of useful plants of one particular use-class. The EIV combines the salience of each species in freelists (cultural data) with its abundance in the different successional stages (ecological data). Fifty three species of plants and one species of fungus were recorded. Through projections of the species informantcurve, a total of 63 species were estimated to make up the Guaymi wild-food-plant cognitive domain. Significant differences in the ethnoecological importance of different successional stages were found. To the Guaymi, the most culturally valuable successional stages, in terms of being sources of wild edible plants, were the mature forests and their edges. Early secondary growth and older secondary forests and their edges were of minor importance.

\section{Introduction}

The Ngöbe or Guaymi people are indigenous to the area between Panama and Costa Rica. While their original territory spanned both countries, during colonial times they were driven out of Costa Rican territories and into Panama (Cooke 1982). During the 1940s, however, the scarcity of land lead to migrations of Guaymi back into Costa Rica (Camacho 1996, Koshear 1995). Currently about 10,000 Guaymi reside in five different communities in Costa Rica (Cordero 2002).

The study took place in the Guaymi Indigenous Reservation of Coto Brus, located on the Pacific mountain range of southern Costa Rica. Elevation ranges between 500 and $1500 \mathrm{~m}$ above sea level. Yearly precipitation averages around 3,500 mm (Gómez 2002), and the vegetation according to Holdridge's life zones is hot-wet transition very humid pre-montane forest (Hartshorn 1983). The preserve encompasses an area of approximately 7,500 hectares and contains a population of around 1,963 people (Casa de la Salud de la Reserva Indigena Guaymi 2003). The Guaymi in the preserve have a subsistence livelihood through small permanent or swidden agricultural plots. Swidden plots are regulated in size by the Costa Rican Government and limited to 1 hectare per year per person within the forest preserve. This policy results in a sparse mosaic of secondary forests varying in age from 5 to $25+$ years embedded within the mature forest of the preserve.

\section{Correspondence}

Héctor Castaneda, School of Natural Resources and Environment, University of Florida, Gainesville, Florida 32611, U.S.A. hectorc@ufl.edu

John Richard Stepp, Department of Anthropology, University of Florida, Gainesville, Florida 32611, U.S.A.

stepp@ufl.edu

Ethnobotany Research \& Applications 5:249-257 (2007) 
The main objectives of the study were to define the composition and structure of the cognitive domain of wild edible plants, and to determine the importance of different successional stages created by swidden practices in providing the Guaymi with wild edible plant species. The main tool for determining habitat importance was the Ethnoecological Importance Index (EIV). This new tool was used to combine cultural data with ecological data in order to assign a cultural value to vegetation types as sources of wild useful plants, in this case wild edible species.

The creation of EIV stems from the need to evaluate ecosystems from a cultural standpoint as to their importance in providing human groups with useful plants in particular use-classes. Existing indices such as the Cultural Significance Index (CSI) created by Turner (1988), and the Phillips' Use Value (UV) (Phillips et al. 1994) evaluate only individual species, or taxonomical groups of plants in terms of their cultural relevance. They do not take into account the ecological distribution and abundance of these plants in the wild. On the other hand, field methods such as those taken by Carneiro (1978) take into account ecological variables of plants, but leave out their cultural value. Similarly, methods such as those used by Salick (1992) evaluate the number of plant uses within different forest types, but do not consider whether plants are abundant or rare in the habitat type. While Salick's approach is recommended for a general ethnobotanical analysis of an area, it does not provide enough detail when comparing habitats as sources of a single type of useful plant.

The approach used by La Torre-Cuardos \& Islebe (2003) combines UV with I.V.I. (importance value index) as a proxy for ecological abundance. The objective of the EIV is very similar to this method with the difference being that it intends to measure only one use category and values species according to their relevance in surveys rather than the number of uses mentioned for each plant.

In view of a lack of appropriate techniques to approach the problem, the EIV was designed to link cultural information for one use category to ecological field data and to focus on habitats rather than plant species. This was done by combining the plants' population density within habitats, with the salience (Smith 1993, Smith \& Borgatti 1997 ) each plant had in freelists as a proxy of their cultural importance.

The null hypothesis for this study is that no significant difference exists in the cultural importance of habitats as sources of wild food plants for the Guaymi of Costa Rica.

\section{Materials and Methods}

In order to study the relationship between successional stages as sources of wild food plants and the Guaymi cul- ture, this research combined both ecological and anthropological data.

The first step consisted of semi-structured interviews using freelists to elicit the cognitive domain of wild plants (Weller \& Romney 1988). Semi-structured interviews were conducted by visiting informants at their homes or fields. These informants were first identified through informant referral by other informants and then selected randomly from that sample. This was done since the community's internal politics often resulted in certain households being unwilling to cooperate with outsiders. Freelists were chosen as a simple way of estimating the prominence each plant species has in the mind of the informant. This assumes that the plants mentioned first and more frequently by informants tend to be the more salient in their cultural domain. Similarly, the distance in rank between plants in the lists was used as a simple proxy for similarity of plants in the cognitive domain (Bernard 1994). Then information on the habitat (type of vegetation) and management practices (i.e. weeding, vine clearing, etc.) regarding each plant was collected. This information was processed using ANTHROPAC $^{\mathrm{tm}}$ (Borgatti 1996).

In order to determine whether the sample was big enough to encompass the majority of the wild edible plants cognitive domain, an informant-species curve was calculated based on the law of diminishing returns (Martin 1995). This was done by bootstrapping (Donovan \& Welden 2002) the results from the freelist 130 times the results of the freelists. The curve was evaluated to estimate the total number of species composing the domain and deciding when the number of interviews was sufficient to cover the majority of plant species within the domain.

Once the species informant curve indicated that the informant sample was sufficient, the next step was to set plots to sample the abundance and frequency of each of the species mentioned in five different types of vegetation. Plants were identified with the aid of a local guide and samples were taken and deposited in the Herbario Juvenal Valerio of the National University of Costa Rica.

Combining the data from the free lists and the field plots, a value of cultural importance was attributed to each type of vegetation according to the wild edible species it contained. The Ethnoecological Importance Value (EIV) is presented in Equation 1. The EIV allows for a quantitative comparison of the ethnoecological value that particular habitats have to different gender, age or cultural groups according to their abundance of wild edible plants.

Equation 1:

$$
\mathrm{EIV}=\sum_{x=1}^{N}(S)\left(n_{x} / N_{x}\right)
$$




\section{Castaneda \& Stepp - Ecosystems as Sources of Useful Plants for the Guaymi 251 People of Costa Rica}

Where:

EIV = Ethnoecological importance value for a particular habitat.

$\mathrm{S}=$ Salience of species $x$ (calculated by Smith's S) (Smith 1993, Smith \& Borgatti 1997).

$\mathrm{N}=$ The total number of species found in the study.

$x=$ The individual species found in the study.

$N_{x}=$ The sum of individuals of species $x$ found in all habitats under study.

$\mathrm{n}_{\mathrm{x}}=$ The total number of individuals of species $\mathrm{x}$ found in one habitat.

Thus, the EIV of a habitat is the sum of the ethnoecological importance of each useful species contained within it. The ethnoecological importance of each species is the product of the species cultural salience (S) times its relative abundance $\left(\mathrm{n}_{\mathrm{x}} / \mathrm{N}_{\mathrm{x}}\right)$.

These are the steps required to determine EIV. For example, a researcher would like to determine the EIV of particular habitats with regards to the medicinal plants they provide to a nearby community.

Step 1: Free lists are conducted in the community and salience (S) is calculated for each species mentioned.

Step 2: Field plots are set in both habitats to reveal the relative abundance $(\mathrm{nx} / \mathrm{Nx})$ of each species.

Step 3: The ethnoecological value of each plant is calculated for each species in each habitat.

Step 4: The ethnoecological value of all species in each habitat is added to determine the EIV.

Since the abundance of each species in each habitat is compared only to the total number of that same species, this method allows the evaluation of plants with different life forms. For example, trees with low number of individuals per hectare, but high biomass per individual, can be included together in the analysis with herbs with high number of individuals but low biomass per individual.

The method has the advantage of being able to estimate the cultural importance of habitats with regards to species within a particular ethnobotanical category in a relatively short time. It is not limited to the use presented here, but can be applied to other ethnobiological categories such as medicinals, fiber, construction materials, dyes, etc. It may also be adapted to evaluate the ethnobiological importance of habitats as sources of useful wildlife. Another use for the EIV is to compare the value that different cultures, or groups within cultures (e.g. age, gender, class) attribute to different habitats according to their biodiversity. In this way, it allows for a useful tool to measure cultural variation within a population. The EIV can be applied in a short period of time to evaluate the ethnobotanical importance of habitats through a relatively simple methodology.
The main limitation of the EIV is that it is only as accurate as the data that it is based on. Possible problems may arise in the free listing if plants are more commonly mentioned because of morphological saliency rather than cultural importance. For example a thorny plant may have edible fruits that are not an important or preferred source of food, but might be more prominent in the informants' minds for its thorns rather than for its value as a food source. Also, the salience of a plant may vary with the time of the year. A plant might be more prominent during its fruiting season than during its sterile period. Another limitation is that the EIV only takes into account the number of plants, and leaves out the amount of edible biomass that it produces. Finally, care must be taken to include all possible habitats used by the people under study. Failure to do so would make it impossible to compare EIV's from one study to the other.

For this study, the EIV for $37510 \times 10 \mathrm{~m}$ field plots was estimated for all the edible plant species mentioned by informants. Individual plants were counted only when they were mature enough to be consumed (this varied according to each species).

The habitat categories under study were: Early secondary forest (1-5 years); older secondary forest (6-25 years); mature forest (25+ years); secondary forest edge; and mature forest edge. These categories corresponded to the local classification of forest habitats and were identified in the field by a knowledgeable informant. The plots were distributed among the five different habitats under study and their location was randomly determined from maps and aerial photographs of the preserve. Finally a Kruskal-Walis analysis (Höft et al. 1999) was conducted to determine if there are significant differences among habitats by comparing all the possible pair combinations of categories.

\section{Results}

\section{Total Number of Species}

After interviewing 46 informants regarding wild edible plants, the informant-species curve shown in Figure 1 was constructed.

A total of 54 plants were identified as wild edibles, including some varieties of single botanical species. The curve in Figure 1 estimates about an $84.12 \%$ of an estimated total of 63 species composing the domain.

The plants identified as wild edibles used by the Guaymi of Coto Brus are presented in Table 1. 


\section{Ethnoecological Importance of Different Vegetation Types}

The Ethnoecological Importance estimated from the field data for each type of vegetation is presented in Figure 2.

The EIV shows that the mature forest edge, due to its abundance of culturally prominent plants, is the most important habitat source of wild food plants.

\section{Discussion}

After evaluating each type of vegetation according to the edible plant species and their respective salience values in Guaymi culture, we found that the most important sources of plant food for the Guaymi are mature forests and their edges (Figure 2). This is confirmed through a Kruskal -Wallis analysis. Mature forest edges have significantly more importance $(\alpha=0.05)$ than all other successional stages thus rejecting the null hypothesis. Mature forests, older secondary edges and early successional stages have no significant differences between them and are therefore considered equally important. Finally, the least important successional stage in terms of wild food plants provided is the older secondary growth, which is significantly different from the mature forest and mature forest edges in this respect. These findings agree with previous studies of different habitats for medicinal plants that generally find that disturbed habitats provide the most important sources (Stepp 2004, Stepp \& Moerman 2001, Voeks 1996).

While edges combine the plants from mature forests with those from early successional stages in a small area, mature forests contain several important plants that are found scarcely or not at all in any other successional stages. Licania belloi Prance, along with all the hearts of palm are good examples.

There may be several reasons why mature forest edges are the most important source of wild food plants for the Guaymi. One of them is access. Since the soils in mature forests are considered the most fertile, shifting cultivation plots are often cleared within it. This creates a space where the Guaymi will constantly interact with for-

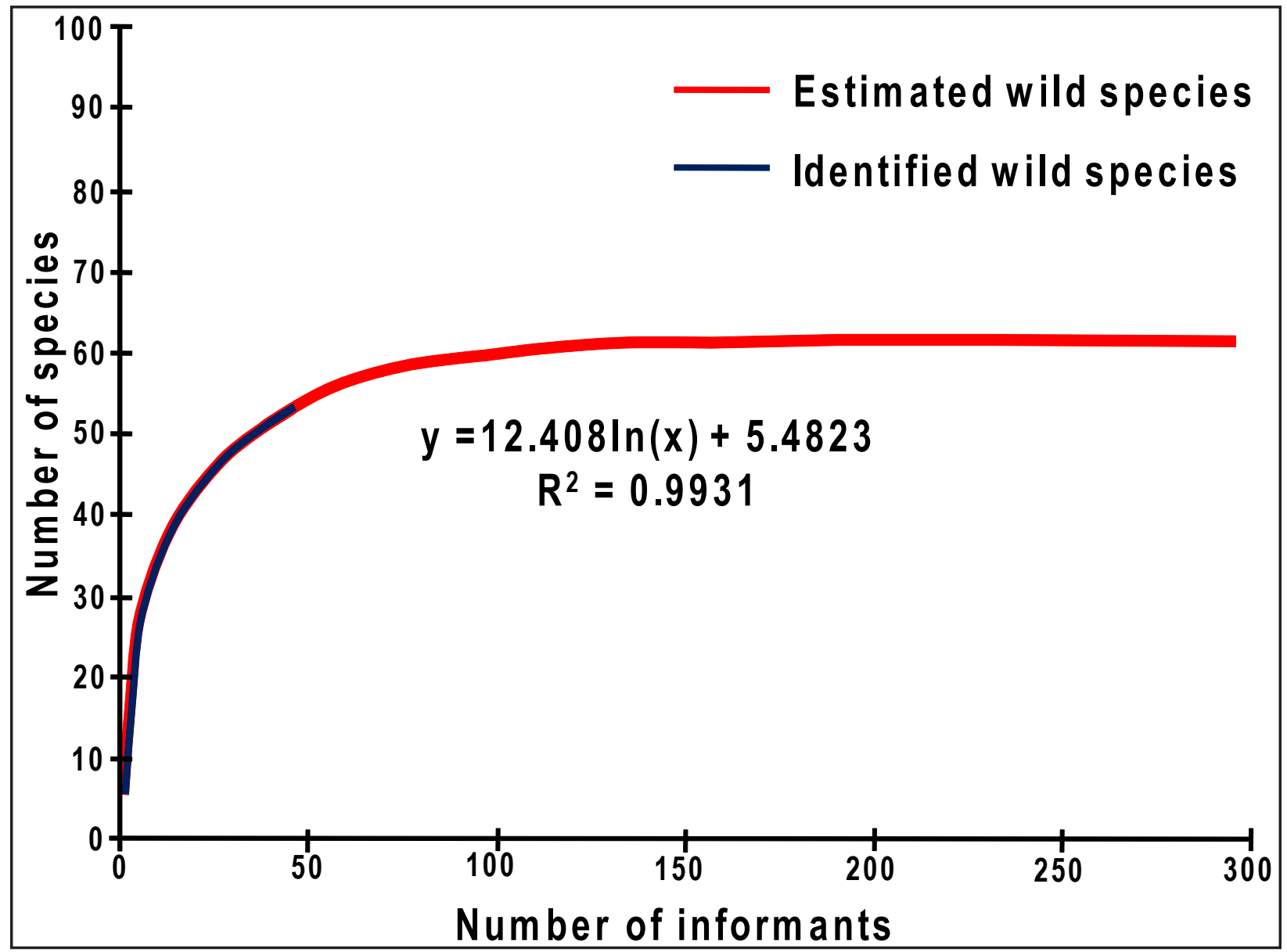

Figure 1. Species informant curve for wild edible plants used by the Guaymi in Coto Brus Costa Rica. 
Castaneda \& Stepp - Ecosystems as Sources of Useful Plants for the Guaymi 253 People of Costa Rica

\begin{tabular}{|c|c|c|c|c|c|c|c|c|c|c|c|c|c|c|c|c|c|c|c|c|c|c|c|}
\hline 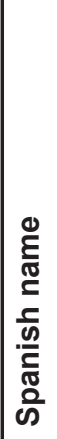 & 응 & 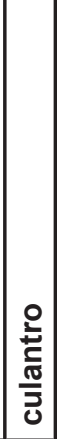 & 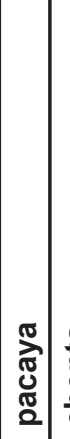 & 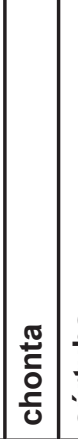 & : & 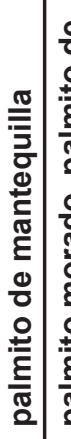 & 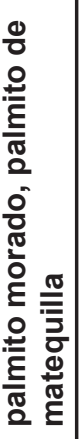 & 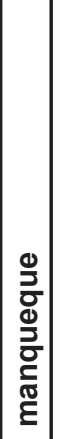 & 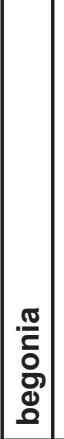 & 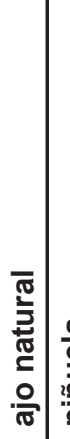 & 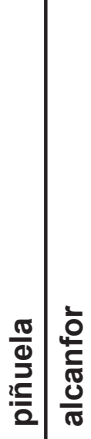 & 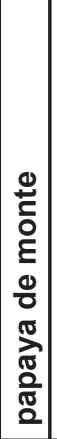 & $\begin{array}{l} \pm \\
0 \\
0 \\
\frac{0}{8} \\
0 \\
0 \\
0\end{array}$ & 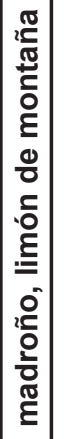 & 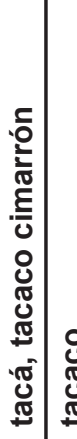 & 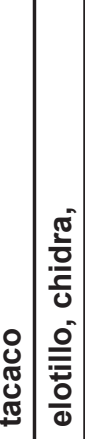 & 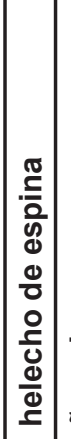 & '. & 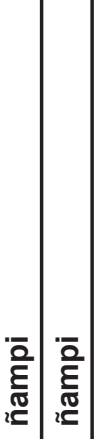 & 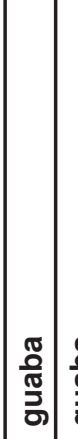 & \begin{tabular}{l|l}
$\frac{\pi}{0}$ & $\frac{\pi}{\pi}$ \\
$\frac{\pi}{\sigma}$ & $\frac{\pi}{2}$ \\
$\frac{\pi}{2}$ & $\frac{\pi}{2}$
\end{tabular} & 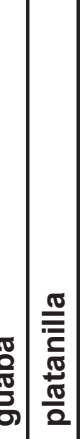 & $\begin{array}{l}\frac{\pi}{\bar{C}} \\
\frac{\pi}{\pi} \\
\frac{\pi}{2}\end{array}$ \\
\hline 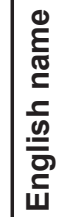 & 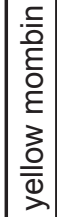 & 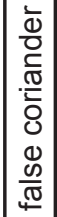 & & 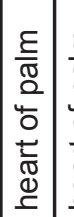 & 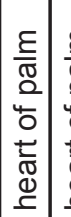 & 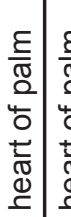 & 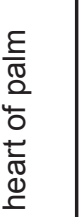 & 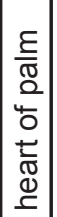 & 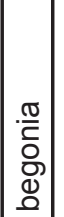 & & & $\begin{array}{l}\frac{\pi}{\sqrt{\sigma}} \\
\frac{2}{\pi} \\
\frac{\alpha}{2} \\
\frac{0}{3}\end{array}$ & & & & & & & 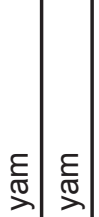 & & & 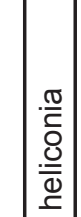 & 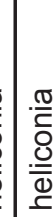 \\
\hline
\end{tabular}

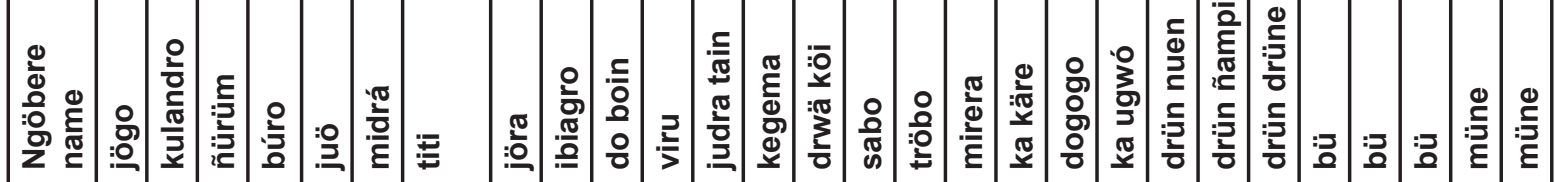

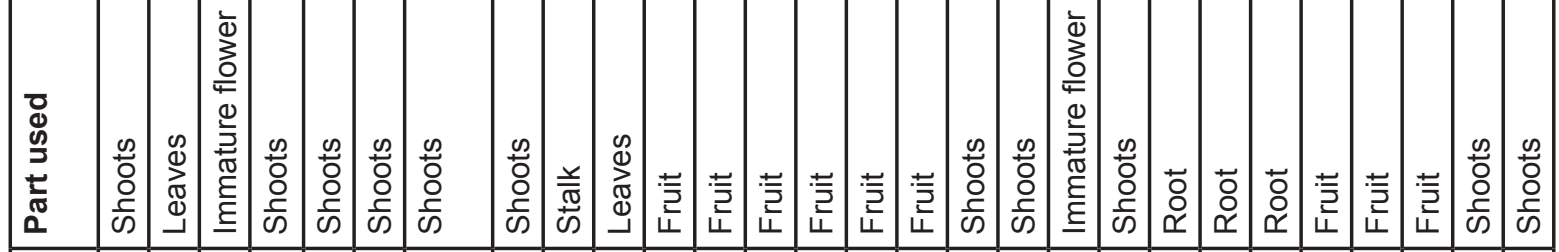

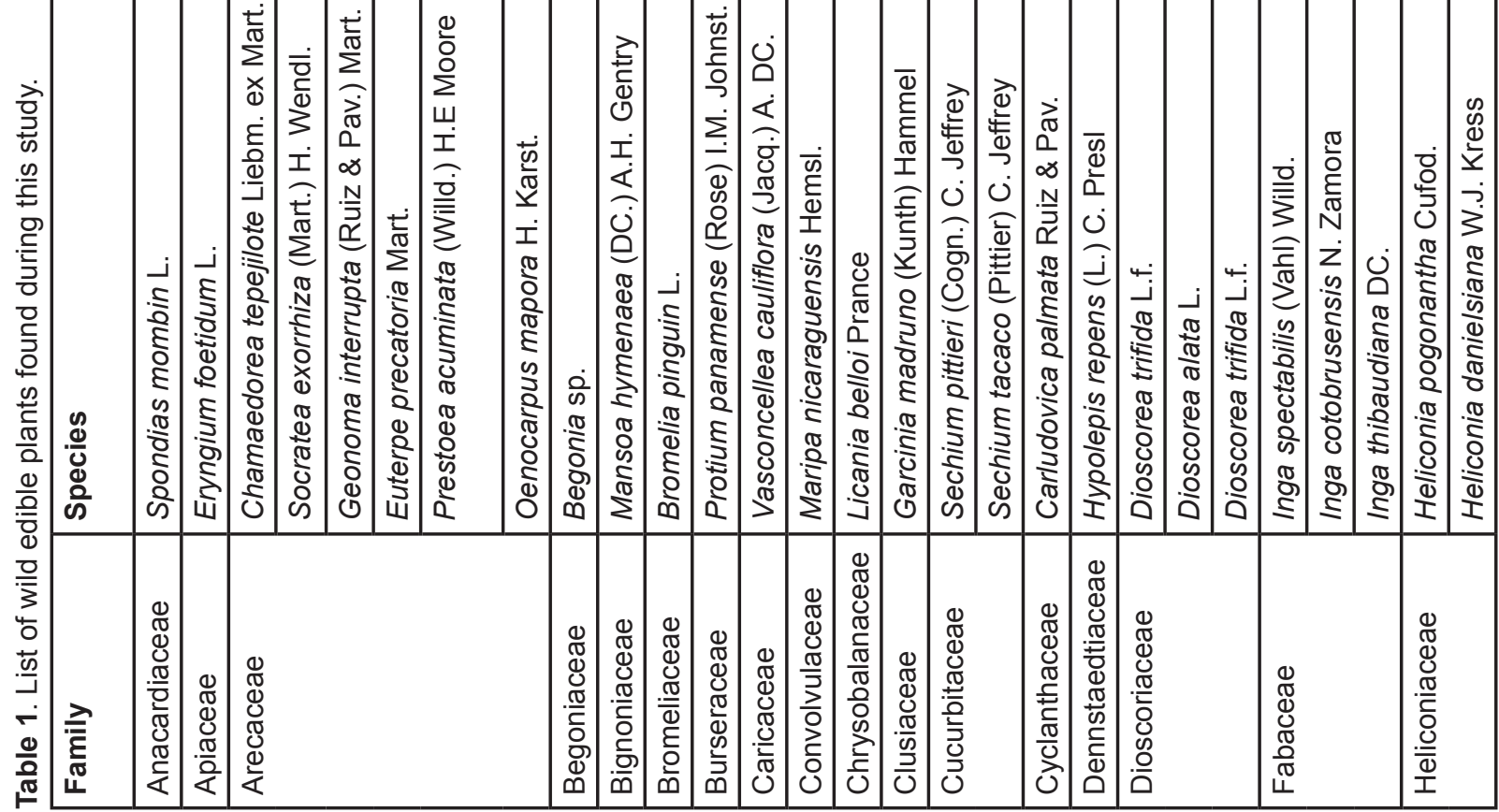

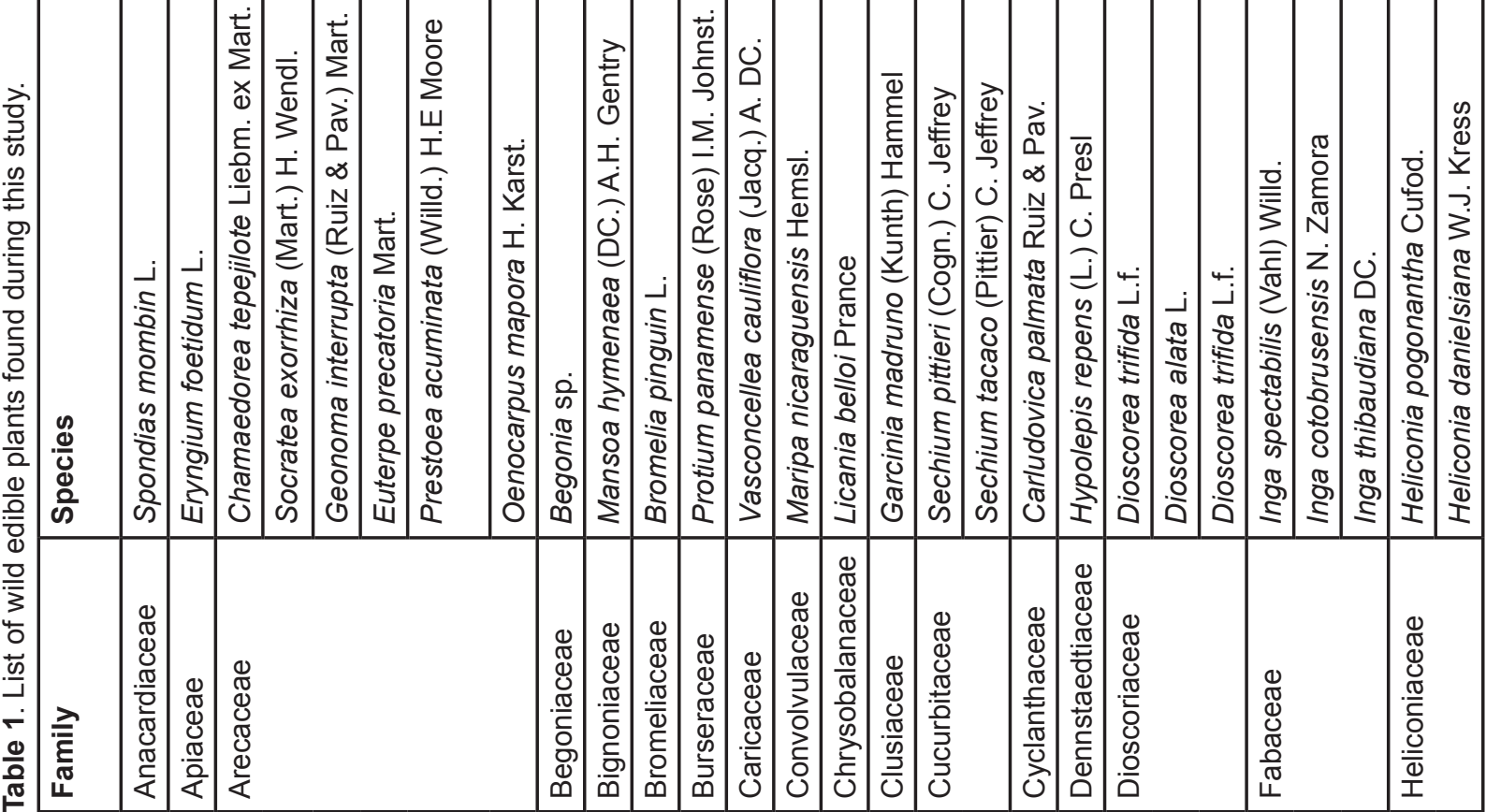

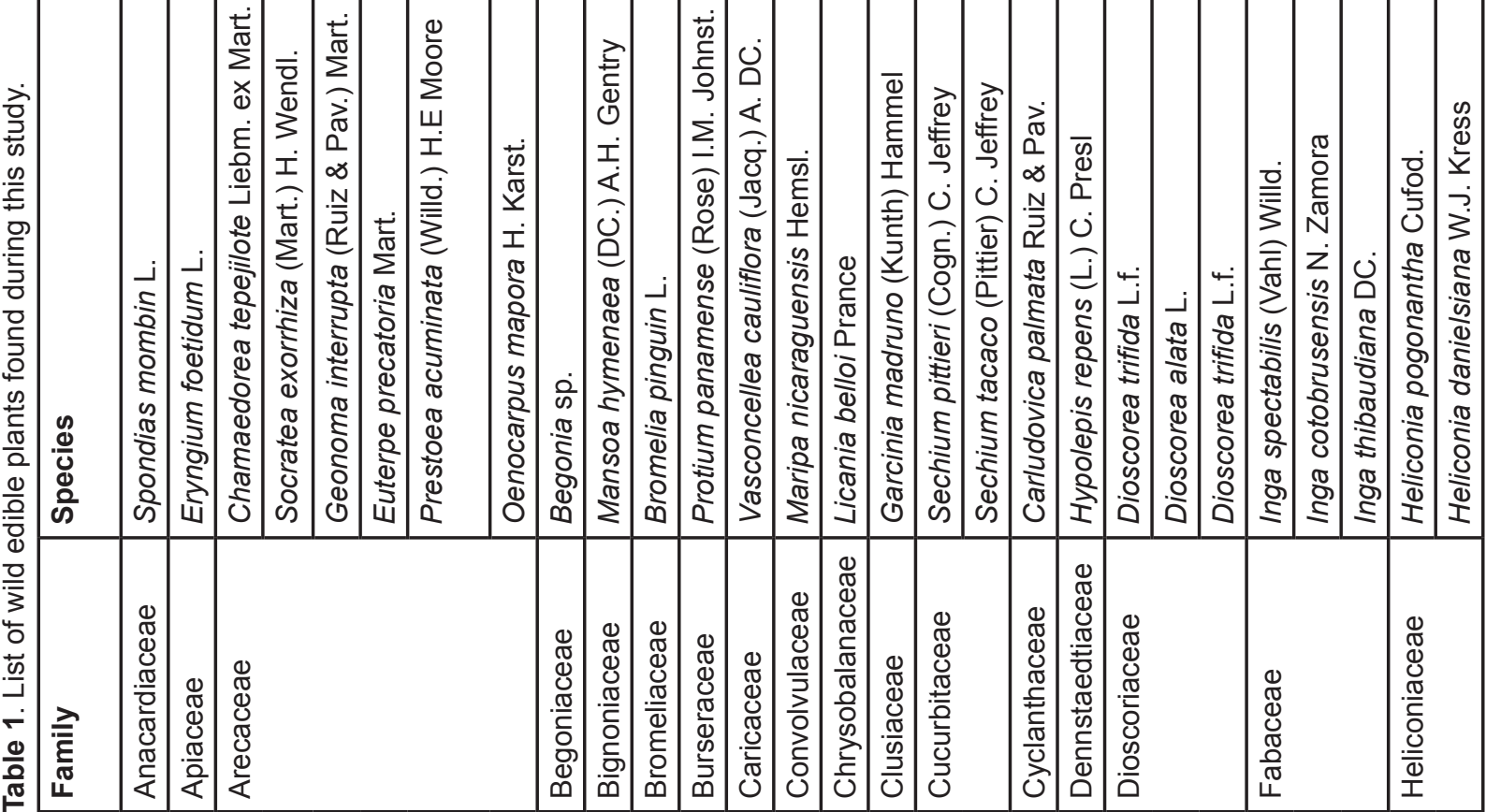

www.ethnobotanyjournal.org/vol5/i1547-3465-05-249.pdf 


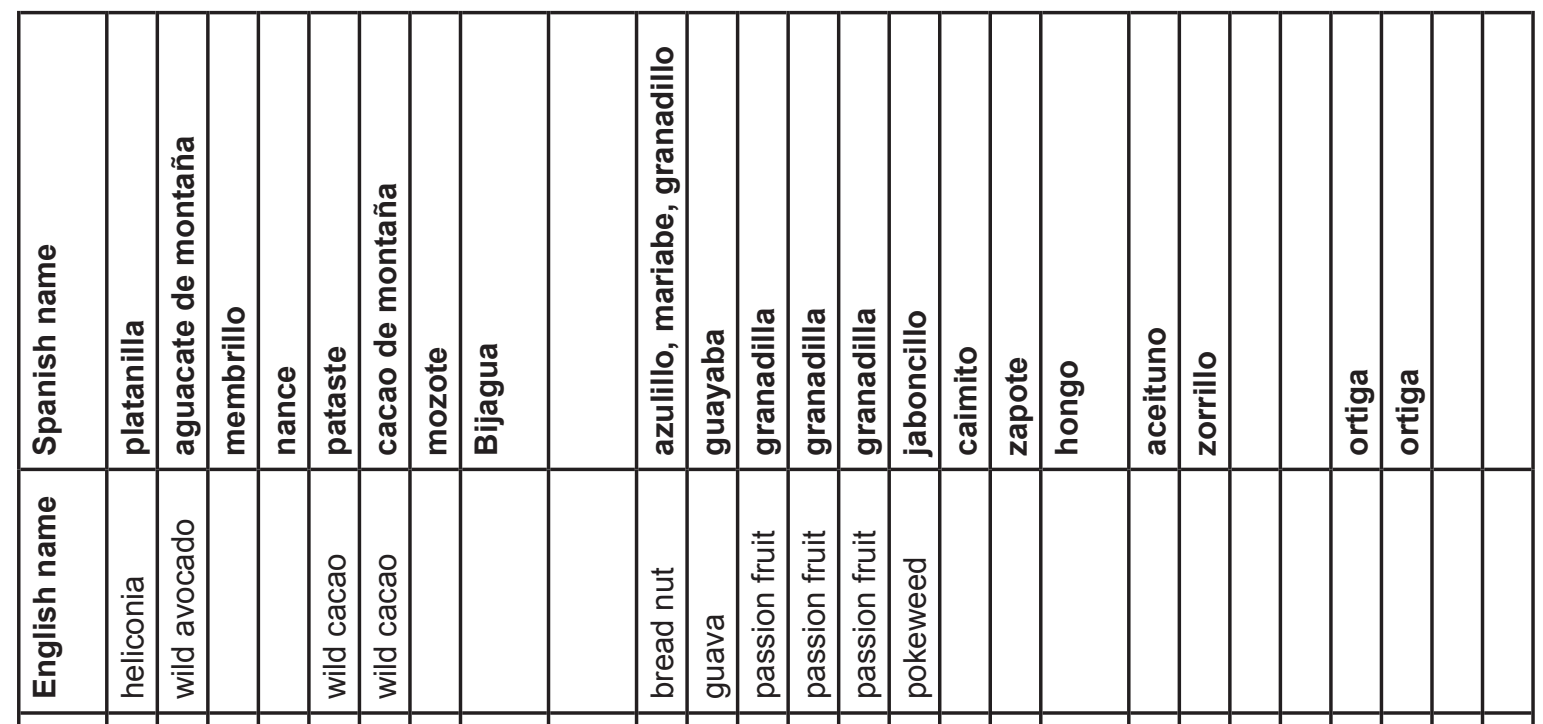

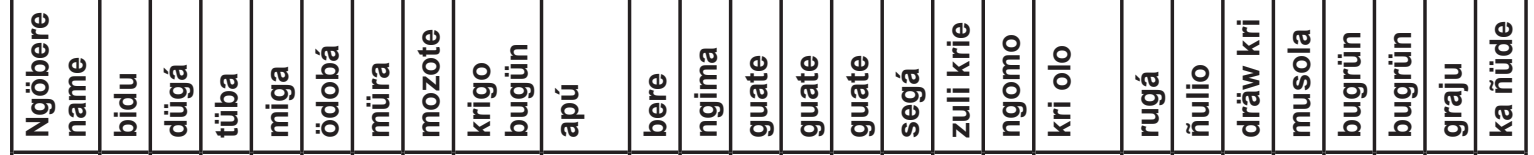

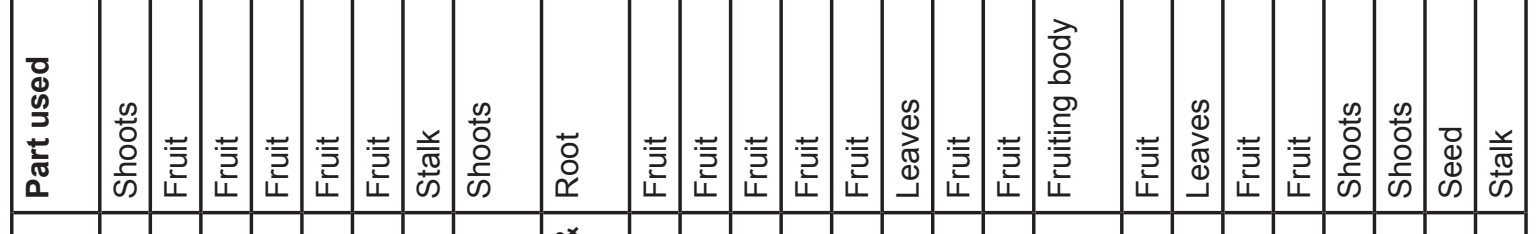

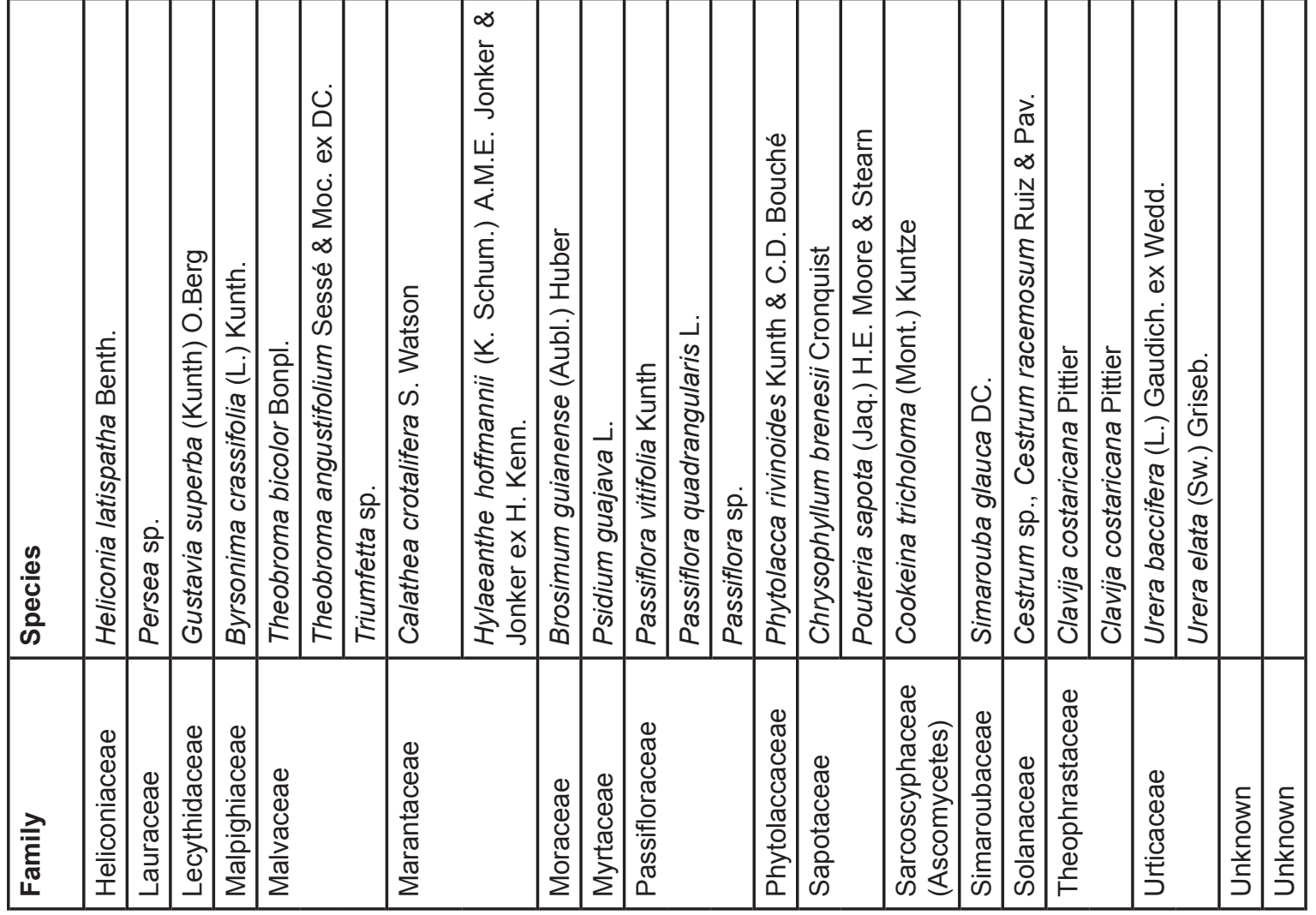




\section{Castaneda \& Stepp - Ecosystems as Sources of Useful Plants for the Guaymi 255 People of Costa Rica}

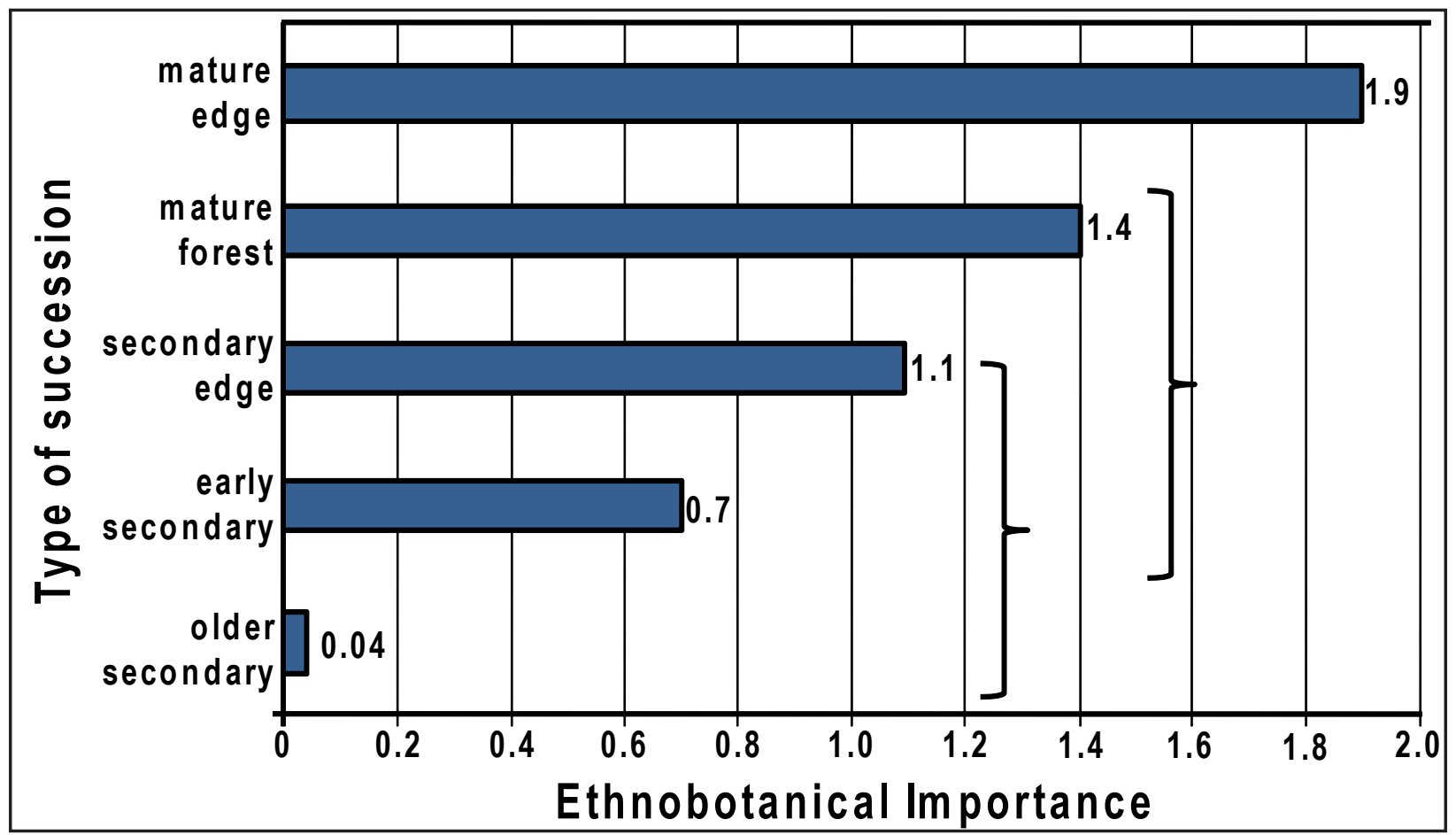

Figure 2. Comparison of the ethnoecological importance of five different vegetation types for the Guaymi of Coto Brus. The brackets present the groups with no significant differences in the EIV to the Guaymi culture.

est edges and have easy access to it. Another possible reason is the combination of habitats that results from the creation of forest edge. Here the species from the mature forest can grow in close proximity with open-sunlight pioneer species. Also, in addition to the mere combination of species, the forest edge habitat often creates condition for a third group of species unique to it (Brothers 1993, Meiners \& Pickett 1999). For example, in this study, Phytolacca rivinoides Kunth \& C.D. Bouché, the most salient species mentioned, was found abundantly only in mature forest edges.

Furthermore, the importance of the mature forest edges may not be only biological in nature but also cultural. Since cultivated fields often create a large area of edge habitat where Guaymi farmers spend considerable amounts of time, it may be the case that Guaymi culture has adapted to using these plants over other wild edibles found in less accessible habitats.

It is interesting to note that many of the plants from the mature forests are considered delicacies, such as hearts of palm and L. belloi, or snacks such as Inga spp. and Clavija costaricana Pittier. On the other hand, plants from the mature forest edges such as Cestrum racemosum Ruiz \& Pav., P. rivinoides, Hypolepis repens C. Presl, and Urera spp. among others, are part of everyday diets since people can gather them from the fields or roadsides at any time.
Although mature forests do not have as much importance as their edges, they are essential in an indirect way. Obviously, there would be no mature forest edges if there were no mature forests. This means that although the forest itself is not as important source of food (since it does not provide everyday foods but rather specialty foods), it is essential in creating the unique edge habitat that provides the most important and diverse source of food plants. Also, many of the species found as remnants in the edges only regenerate under mature forest conditions (hence the lack of similarity between the species composition of secondary and mature forest edges). Mature forests also serve as sources of seeds for plants in secondary successions.

\section{Conclusions}

The wild edible plants cognitive domain for the Guaymi is estimated to be approximately 63 species. There is a significant difference in the cultural value of different successional stages as sources of wild edible plants for the Guaymi. Mature forests, and particularly their edges present the highest EIV's.

Farming techniques shape the environment and vice versa. From a systems perspective, shifting cultivation as practiced by the Guaymi plays an important role in creating habitat for culturally important wild edible plant species. The edges created by the clearing of fields in the 
mature forests not only provide the conditions for plant species with different environmental requirements, but also creates an accessible inter-phase where humans can easily collect them for consumption. It is likely as well that the Guaymi culture has also adapted to this system by favoring the use of the species found in these types of vegetation.

The growing demand for land by the increasing Guaymi population and their incorporation into the market economy promotes the adoption of more permanent uses of the land such as cattle, coffee and other intensive cash crops. This means the current system, where the mixture of disturbed and mature vegetation creates the environment for wild edible plants, may be endangered and with it the ethnobotanical knowledge of these and other nontimber forest products.

This is the case of the Guaymi of Coto Brus, Costa Rica, but the principle could be extrapolated to other cultures reliant upon shifting cultivation and under similar socioeconomic conditions as the Guaymi. Judging by the diversity of wild edibles reported for other Costa Rican indigenous groups such as the Cabecar and the Bribri (García-Serrano \& Del Monte 2004), it is likely that other cultures would have developed a similar relationship with their environment relying more on the vegetation of the forest edges than on exclusively mature or secondary forests. Further studies are needed to confirm this hypothesis.

As with the case of the Huastec Maya in Mexico (Alcorn 1981) and numerous other indigenous groups, the vegetation that surrounds the Guaymi, even that considered to be mature forest, is mostly anthropogenic in origin. Even though the current management for wild resources may not be as conscious as in other cultures, the plants that compose each successional stage are all influenced by swidden agriculture. If this management could become more conscious in Guaymi society, then a better utilization of resources could be achieved. Further study should center on ecology, cultural perception, nutritional properties and possible domestication of the wild edible plants identified in this study.

\section{Acknowledgements}

Special thanks to Hugh Popenoe as chair of the thesis that originated this investigation. We are very grateful to María Bejarano and Alejandro Palacios of the Guaymi Indigenous reserve for helping us with lodging at their home and helping us during field work. Also, we give special acknowledgment to Luis Diego Gómez for his valuable help in providing contacts, advice, and logistics aid to our work. We are also thankful for the aid and support given to us by Rodolfo Quirós, Emilce Ramirez, and all the staff of Las Cruces Biological Station (Organization for Tropical Studies). We also thank Luis Poveda and Pablo Sánchez at the Juvenal Valerio Herbarium for their help in identifying plant material. Finally, this research would have not been possible without the financial support of the Fulbright Program of the United States Department of State and the Ford Foundation, whose support was provided through the Tropical Conservation and Development Program at the University of Florida.

\section{Literature Cited}

Alcorn, J.B. 1981. Huastec noncrop resource management. Human Ecology 9:395-417.

Borgatti, S. 1996. Anthropac 4.0. Analytic Technologies, Natick, Massachusetts.

Bernard, R. 1994. Research Methods in Anthropology, Qualitative and Quantitative Approaches. Sage Publications, Thousand Oaks, California.

Brothers, T.S. 1993. Fragmentation and Edge Effects in Central Indiana Old-growth Forests. Natural Areas Journal 13(4):268-275.

Camacho, N. C. 1996. En la Frontera del Siglo XX: La exclusión de los Guaymies en Costa Rica. Universidad de Costa Rica, San José, Costa Rica.

Carneiro, R. L. 1978. The Knowledge and Use of Rainforest Trees by the Kuikuru Indians of Central Brazil. Pp 202216 in The Nature and Status of Ethnobotany Anthropological papers 67. Edited by R.I. Ford, Museum of anthropology, University of Michigan, Ann Arbor, Michigan.

Casa de la Salud de la Reserva Indigena Guaymi. 2003. pers. comm., Consultation of Census Records Conducted by the Local Health Unit.

Cooke, R. 1982. Los Guaymíes si Tienen Historia. Pp. 2764 in Centro de Estudios y Acción Social (CEASPA). Editors, El Pueblo Guaymi y Su Futuro. Ciudad de Panamá, Panamá

Cordero, A. 2002. Mujeres Talamanqueñas Costarricences y la Biodiversidad. Pp 286-292 in Genero y Biodiversidad en Comunidades Indígenas en Centroamerica. Edited by C. Dary, Facultad Latinoamericana de las Ciencias Sociales, Cuidad de Guatemala, Guatemala.

Donovan, T. \& C. Welden. 2002. Spreadsheet Exercises in Ecology and Evolution. Sinauer Associates, Inc., Sunderland, Massachusetts.

Gómez, L.D. 2002. Las Cruces Biological Station (Organization for Tropical Studies) metiorlogical data base. www. ots.duke.edu/en/lascruces/meterological.shtml. 


\section{Castaneda \& Stepp - Ecosystems as Sources of Useful Plants for the Guaymi 257 People of Costa Rica}

Hartshorn, G.S. 1983. Plants. Pp 118-157 in Costa Rican Natural History. Edited by D.H. Janzen, University of Chicago Press, Chicago, Illinois.

Höft, M., S.K. Barik \& A.M. Lykke. 1999. Quantitative Ethnobotany: Applications of multivariate and statistical analyses in ethnobotany. People and Plants Working Paper 6. United Nations Educational, Scientific and Cultural Organization (UNESCO). Paris, France.

Koshear, J. 1995. Guaymi Agriculture, Forest Utilization and Ethnbotany in Coto Brus, Costa Rica: An analysis of sustainability. Ph.D. Dissertation. University of California, Berkeley.

La Torre-Cuadros, M. \& G.A. Islebe. 2003. Traditional Ecological Knowledge and Use of Vegetation in Southeastern Mexico: A case study from Solferino, Quintana Roo. Biodiversity and Conservation 12(12):2455-2476.

Martin, G. 1995. Ethnobotany: A methods manual. Chapman \& Hall, London.

Meiners, S.J. \& S.T.A. Pickett. 1999. Changes in Community and Population Responses Across a Forest-field Gradient. Ecography 22(3):261-267.

Phillips, O., A.H. Gentry, C. Reynel, P. Wilkin \& C. GalvezDurand B. 1994. Quantitative Ethnobotany and Amazonian Conservation. Conservation Biology 8(1):225-248.

Ramos, C. \& J.P. Del Monte. 2004. The Use of Tropical Forest (Agroecosystems and Wild Plant Harvesting) as a Source of Food in the Bribri and Cabecar Cultures in the Caribean Coast of Costa Rica. Economic Botany 58 (1):58-71.

Salick, J. 1992. Amuesha Forest Use and Management: An integration of infigenous forest use and natural forest management. Pp 305-332 in Conservation of Neotropical Forests: Working from traditional resource use. Edited by K. H. Redford and C. Padoch, Columbia University Press, New York.

Smith, J.J. 1993. Using Anthropac 3.5 and a Spreadsheet to Compute a Free-list Salience Index. Cultural Anthropology Methods 5(3):1-3.

Smith, J.J. \& S.P. Borgatti. 1997. Salience Counts - And So Does Accuracy: Correcting and updating a measure of free-listing-item salience. Journal of Linguistic Anthropology 7(2):208-209.

Stepp, J.R. 2004. The Role of Weeds as Sources of Pharmaceuticals. Journal of Ethnopharmacology 92:163-66.
Stepp, J.R. \& D.E. Moerman. 2001. The Importance of Weeds in Ethnopharmacology. Journal of Ethnopharmacology 75:19-23.

Turner, N. J. 1988. "The Importance of a Rose": Evaluating the cultural significance of plants in Thompson and Lillooet Interior Salish. American Anthropologist 90:272290.

Voeks, R. A. 1996. Tropical Forest Healers and Habitat Preference. Economic Botany 50:381-400

Weller, S.C. \& A.K. Romney. 1988. Systematic Data Collection. Sage Publications, Newbury Park, California. 